Alma Mater Studiorum - Università di Bologna DEPARTMENT OF ECONOMICS

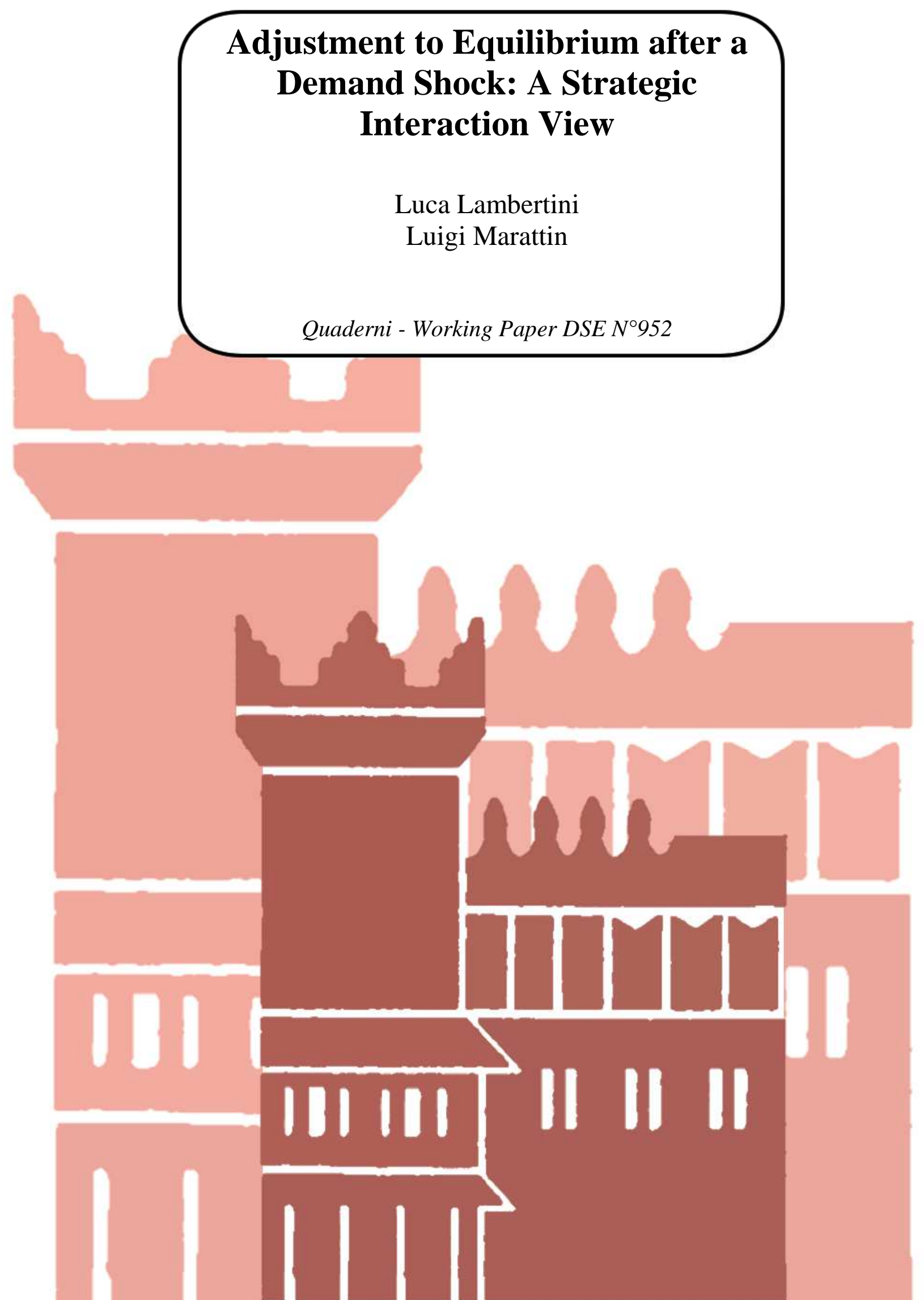




\title{
Adjustment to Equilibrium after a Demand Shock: A Strategic Interaction View*
}

\author{
Luca Lambertini ${ }^{\dagger} \quad$ Luigi Marattin ${ }^{\ddagger}$
}

June 27, 2014

\begin{abstract}
In this paper we verify the functioning of the standard neoclassical adjustment to equilibrium after a demand shock in a non-cooperative simultaneous Cournot duopoly with complete, symmetric and imperfect information. Our results show that in such a framework the adjustment to the long-run level of output by the entire industry or part of it is no longer guaranteed. We show that the size of the demand shock determines the nature and number of equilibria generated by strategic interaction, whereas the post-adjustment real wage level determines which equilibrium is actually obtained.
\end{abstract}

JEL Codes: D43; E30

Keywords: Cournot duopoly, wage adjustment, demand shock.

\footnotetext{
*We would like to thank Giuseppe Pignataro for a profitable discussion on the original idea. The usual disclaimer applies.

$\dagger$ Department of Economics, University of Bologna. Strada Maggiore 45, 40126 Bologna, Italy. Email: luca.lambertini@unibo.it

${ }_{\ddagger}^{\ddagger}$ Department of Economics, University of Bologna. Strada Maggiore 45, 40126 Bologna, Italy. Email: luigi.marattin@unibo.it
} 


\section{Introduction}

Much of modern macroeconomic theory is based on the neoclassical adjustment mechanism to long-run equilibrium whenever a permanent demand shock moves the economy away from it (Blanchard and Fisher 1989, Woodford 2003, Benigno 2009). The adjustment process is essentially based on output gap-induced movements in production costs (mostly nominal wages) which - coeteris paribus - change firms' profit perspectives and therefore shift the short-run aggregate supply curve along the new demand schedule, thereby bringing back output to its natural level. Under nominal rigidities, if a negative (positive) demand shock occurs, the wage level decreases (increases) over time because the economy is operating below (above) the NAWRU potential level (Holden and Nymoen 2002, Baghli 2007). This, in turn, increases (decreases) profits and therefore increases (decreases) the incentive to expand supply. At the end of the adjustment process, the new equilibrium displays an aggregate output level back to its long-run value, with a permanently lower (higher) price level.

Being a cornerstone of neoclassical economics, the above-described adjustment process has been used to develop many theories which lie at the core of policy prescriptions in several areas. For example, Optimal Currency Area theory (Mundell 1961, McKinnon 1963, Kenen 1969) states that countries wishing to give up their national monetary policies to adopt a single currency must have enough labour market flexibility so to ease the adjustment mechanism after an asymmetric demand shock. Should such a flexibility - especially on wages - be absent, retaining macroeconomic policy at the national level is necessary for the purpose of optimal business cycle stabilization.

In this paper we pose a simple question: in a non-competitive market structure, is there any equilibrium outcome preventing the economy from returning to the pre-shock equilibrium output after a permanent demand shock? Particularly, we use a standard Cournot setting with homogenous good where, after the occurrence of a negative demand shock, two identical firms (as a consequence of an unmodelled bargaining process with labor unions) face the following choice: either to increase production at a lower nominal wage (thereby pushing the equilibrium back to its pre-shock level but at a lower price) or sticking to the level of output (and price) in place after the demand shock.

Our results show that - under very general assumption on technology - the equilibrium outcome depends on the level that the real wage would achieve 
at the end of the adjustment process, if the latter actually were to occur. The size of the demand shock shapes the set of pure- and mixed-strategy equilibria that are actually achievable. Obviously the individual firm must have full knoweldge of two factors: (i) the level of the real wage that it would face if it were to adjust production ii) the profit function of the rival. Formally, we employ a non-cooperative simultaneous game with complete, symmetric but imperfect information, which is the game-theoretical counterpart of the assumption of rational expectations for the macroeconomic equilibrium.

The remainder of this paper is organized as follows. Section 2 lays out the theoretical setting and the general framework of our research question; section 3 models the strategic interaction between the two firms and section 4 carries out the equilibrium analysis. While section 5 sums up our results, section 6 offers some concluding remarks.

\section{Setup}

The economy is composed by two identical firms (indexed by $i=1,2$ ) producing a homogeneous good. Firms play a two-stage game in which the first is played in discrete strategies and requires firms to choose whether to adjust or not to a demand shock, and the second is the market stage. As usual, the model will be solved by backward induction, looking first at firms' behaviour in the market subgames. To this aim, we have to describe the structure of demand and technology. The good is homogeneous and produced according to the following technology:

$$
q_{i}=L_{i}^{\alpha}
$$

where $L_{i}$ indicates the amount of labor employed by firm $i$ and $\alpha>0$ the degree of returns to scale. demand and cost functions are respectively:

$$
\begin{aligned}
p & =a_{0}-Q=a_{0}-q_{1}-q_{2} \\
C_{i} & =\omega q_{i}
\end{aligned}
$$

Accordingly, the only component of marginal cost is assumed to be the unit real wage $\omega$, which is the ratio between nominal wage $w$ and the aggregate price index $\mathbb{P}$ which is a standard Dixit-Stiglitz aggregator. Nominal wage contracts are staggered so that $w$ is fixed in the short term and it is subject to revision at the next round of the (unmodelled) bargaining process between firms and labor union. Whenever the economic system - of which the sector 
we are looking at is a component - is hit by a shock, $p$ and $\mathbb{P}$ move in the same direction. For this reason, in the remainder we will confine our attention to variations in $p$ without further reference to $\mathbb{P}$. Firm $i$ 's profit function is $\pi_{i}=(p-\omega) q_{i}$.

For future reference, it is useful to stress here that, in this model, $\omega$ is marginal cost and therefore, borrowing a label commonly used in the theory of industrial organization, $a_{0}-\omega$ is a measure of market size. Figure 1 depicts the adjustment process that takes place in the economy after a negative demand shock. We will use this Figure as main reference for the rest of the paper.

Figure 1 The adjustment process at work in the $Q, p$ space

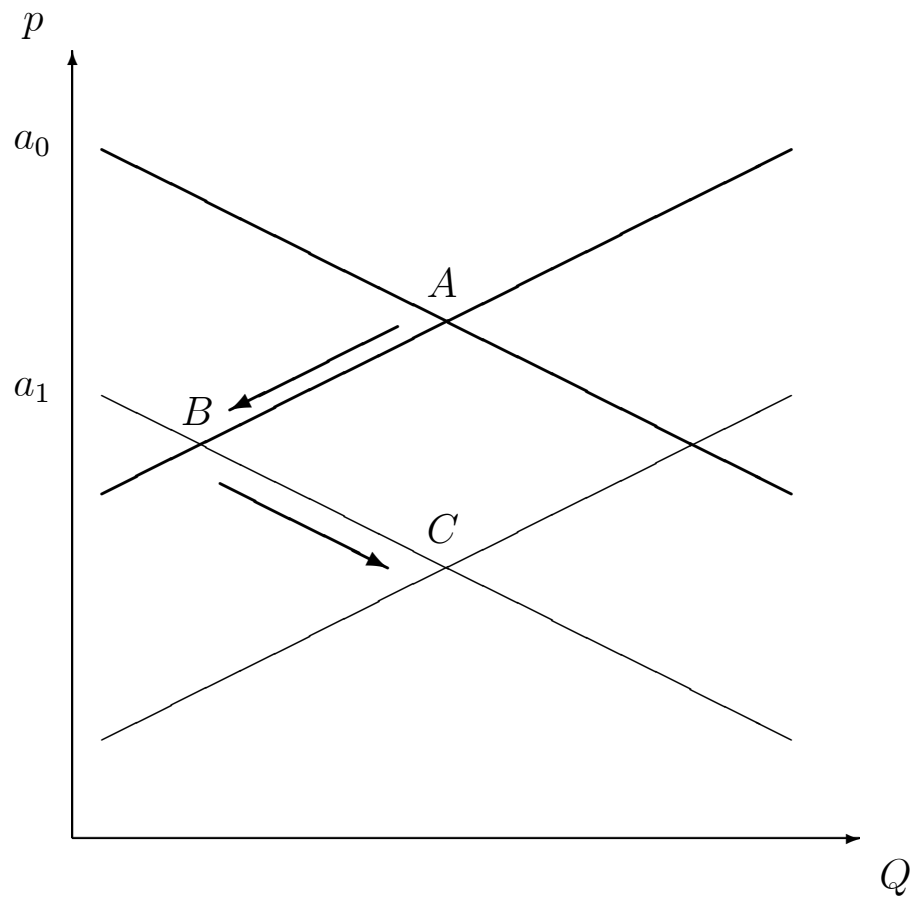

Initial equilibrium is in point $A$, that we assume to represent the long run natural level of output (Woodford 2003). Then the economy is hit by an 
exogenous negative demand shock that shifts the equilibrium to point $B$. At this point the standard neoclassical adjustment process would dictate that, following the decrease in nominal wage caused by capacity underutilization (or, equivalently, expectations of lower prices), firms increase production and shift the supply curve to point $C$. Then, output would be back to the preshock level and price level would be permanently lower. The contribution of this paper is to verify whether the shift from point $B$ to point $C$ is actually always consistent with strategic behaviour in a Cournot-duopoly setting.

In point $A$, Nash equilibrium is characterized as follows. Each firm hires the amount of labor $L^{A}$, produces the quantity $q^{A}$, and earns profits $\pi^{A}$ such that:

$$
\begin{aligned}
L^{A} & =3^{-\frac{1}{\alpha}}\left(a_{0}-\omega_{A}\right)^{\frac{1}{\alpha}} \\
q^{A} & =\left[\frac{\left(a_{0}-\omega_{A}\right)}{3}\right]^{\alpha} \\
\pi^{A} & =\frac{\left(a_{0}-\omega_{A}\right)}{3}\left[a_{0}-\omega_{A}-2\left(\frac{\left(a_{0}-\omega_{A}\right)}{3}\right)\right]
\end{aligned}
$$

Nominal wage is $w_{A}$, prices $p_{A}$ and real wage $\omega_{A}$. We then assume a negative demand shock, which shifts the vertical intercept of the demand schedule to $a_{1}<a_{0}$, moving instantaneously the equilibrium to point $B$ of Figure 1 . Nominal wage is fixed because of staggered labor contracts, but price level has decreased to $p_{B}<p_{A}$, so that real wage is $\omega_{B}>\omega_{A}$. Labor, quantity and profits in point $B$ are:

$$
\begin{aligned}
L^{B} & =3^{-\frac{1}{\alpha}}\left(a_{1}-\omega_{B}\right)^{\frac{1}{\alpha}} \\
q^{B} & =\left[\frac{\left(a_{1}-\omega_{B}\right)}{3}\right]^{\alpha} \\
\pi^{B} & =\frac{\left(a_{1}-\omega_{B}\right)}{3}\left[a_{1}-\omega_{B}-2\left(\frac{\left(a_{1}-\omega_{B}\right)}{3}\right)\right]
\end{aligned}
$$

Because of nominal rigidities, the economy is now operating below its natural level. Standard neoclassical theory says that this generates a downward pressure on nominal wage, coming from either a Walrasian or non-competitive labour market. Under sticky wages, such a pressure will be accomodated at the next round of wage contract negotiations; this will reduce marginal costs for firms and therefore push them to increase production until the new equilibrium is reached in point $C$. We instead assume that in point $B$ firm $i$ faces 
a strategic choice: it can choose between expanding the scale of production at a lower nominal wage, or rather keeping the level of output unchanged at point $B$ with the wage fixed. We can interpret such a choice as the outcome of a bargaining process with trade unions: more jobs in exchange of lower wages or higher wages (i.e., keep the wages at the same level as before the occurrence of the shock) with fewer jobs. Such a structure can be reconciled with the classical modelling of wage bargaining and employment (such as McDonald and Solow 1981), where the bargaining process between a monopolist union maximizing some form of utility function and a firm expressing its profit-maximizing labor demand schedule endogenously gives rise to a trade off between real wage and employment. If the entire industry adjusts wages (and consequently outputs), the resulting symmetric equilibrium is represented by point $C$ in Figure 1, where nominal wage will have gone down to $w_{C}$ and prices down to $p_{C}\left(<p_{B}<p_{A}\right)$. Individual profits and quantities in $C$ are given by:

$$
\begin{aligned}
\pi^{C} & =\frac{\left(a_{1}-\omega_{C}\right)}{3}\left[a_{1}-\omega_{C}-2\left(\frac{\left(a_{1}-\omega_{C}\right)}{3}\right)\right] \\
q^{C} & =\left[\frac{\left(a_{1}-\omega_{C}\right)}{3}\right]^{\alpha}
\end{aligned}
$$

\section{Modelling strategic interaction}

We now define smart the firm which, after the negative demand shock, decides to adjust production, thereby internalizing the decrease in nominal wage, and myopic the firm which does not. A firm's profits are therefore defined as follows:

$$
\begin{aligned}
\pi_{S j}\left(\omega_{C}, \omega_{B}\right) & =\left(a_{1}-q_{S}-q_{j}-\omega_{C}\right) q_{S} \\
\pi_{M j}\left(\omega_{B}, \omega_{C}\right) & =\left(a_{1}-q_{M}-q_{i}-\omega_{B}\right) q_{M}
\end{aligned}
$$

where subscripts $M$ and $S$ stand for myopic and smart, respectively. Accordingly, depending on $i, j=S, M$, we have four alternative outcomes, $\{(M, M),(S, S),(M, S),(S, M)\}$, two of which are obviously equivalent up to a permutation of firms. Outcome $(M, M)$, in which both firms behave myopically, corresponds to point $B$ in Figure 1 , where profits are $\pi_{M M}\left(\omega_{0}, \omega_{0}\right)$ whose value is given by equation $(9)$; outcome $(S, S)$, where both firms are 
smart and their output strategies incorporate the wage adjustment, corresponds to point $C$ of the same graph and it generates profits $\pi_{S S}\left(\omega_{C}, \omega_{C}\right)$, given by equation (10).

There remains to investigate the asymmetric perspective in which one firm is smart and the other is myopic and does not perform the wage adjustment. ${ }^{1}$ In such a case, one firm sticks to the same quantity which is relevant in $B$, supplying $q_{M S}=q^{B}=\left[\left(a_{1}-\omega_{B}\right) / 3\right]^{\alpha}$, while the other sets $q_{S M}$ to maximise

$$
\pi_{S M}\left(\omega_{C}, \omega_{B}\right)=\left[a_{1}-q_{S M}-\left[\frac{\left(a_{1}-\omega_{B}\right)}{3}\right]^{\alpha}-\omega_{C}\right] q_{S M},
$$

which delivers:

$$
\pi_{S M}\left(\omega_{C}, \omega_{B}\right)=\frac{1}{9} 4^{-\frac{1}{\alpha}}\left(2^{\frac{1}{\alpha}}-1\right)\left(2 a_{1}+\omega_{B}-3 \omega_{C}\right)^{2}>0
$$

Conversely, the myopic firm does not adjust production and keeps paying the initial nominal wage rate $w_{B}>w_{C}$. So its profits read as follows:

$$
\pi_{M S}\left(\omega_{B}, \omega_{C}\right)=\frac{1}{9}\left(a_{1}-\omega_{B}\right)\left[2 a_{1}-2 \omega_{B}-2^{-\frac{1}{\alpha}}\left(2 a_{1}+\omega_{B}-3 \omega_{C}\right)\right]>0 .
$$

Having fully characterised the spectrum of market subgames and their outcomes, we may look up to the first stage of the game, where each firm has to decide whether to adjust or not to the demand shock, i.e., whether to renegotiate the wage and therefore reformulate its production plan. The upstrem stage is therefore played in the discrete strategy space $(M, S)$, and

\begin{tabular}{|c|c|c|}
\hline \multirow{3}{*}{$\begin{array}{c}M \\
S\end{array}$} & M & $S$ \\
\hline & $\pi_{M M}\left(\omega_{B}, \omega_{B}\right) ; \pi_{M M}\left(\omega_{B} ; \omega_{B}\right)$ & $\pi_{M S}\left(\omega_{B} ; \omega_{C}\right) ; \pi_{S M}\left(\omega_{C} ; \omega_{B}\right)$ \\
\hline & $\pi_{S M}\left(\omega_{C} ; \omega_{B}\right) ; \pi_{M S}\left(\omega_{B} ; \omega_{C}\right)$ & $\pi_{S S}\left(\omega_{C} ; \omega_{C}\right) ; \pi_{S S}\left(\omega_{C} ; \omega_{C}\right)$ \\
\hline
\end{tabular}
is summarised by the following $2 \times 2$ Matrix.

2

\section{Matrix 1}

The equilibrium outcome(s) and Pareto-efficiency (whenever the latter property is indeed relevant) are determined by the signs of the following

\footnotetext{
${ }^{1}$ It is worth stressing that this outcome does not correspond to any of the points represented in Figure 1.
} 
expressions:

$$
\begin{aligned}
\pi_{M M}\left(\omega_{B}, \omega_{B}\right)-\pi_{S M}\left(\omega_{C} ; \omega_{B}\right) & =\frac{1}{9}\left[\begin{array}{c}
\left(a_{1}-\omega_{B}\right)^{2}+ \\
4^{-\frac{1}{\alpha}}\left(1-2^{\frac{1}{\alpha}}\right)\left(2 a_{1}+\omega_{B}-3 \omega_{C}\right)^{2}
\end{array}\right] \\
\pi_{M S}\left(\omega_{B} ; \omega_{C}\right)-\pi_{S S}\left(\omega_{C} ; \omega_{C}\right) & =\frac{1}{9}\left[\begin{array}{c}
\left(a_{1}-\omega_{B}\right) 2 a_{1}-2 \omega_{B}+ \\
-2^{-\frac{1}{\alpha}}\left(2 a_{1}+\omega_{B}-3 \omega_{C}\right)-\left(a_{1}-\omega_{C}\right)^{22}
\end{array}\right] \\
\pi_{S S}\left(\omega_{C} ; \omega_{C}\right)-\pi_{M M}\left(\omega_{B}, \omega_{B}\right) & =\left(\frac{1}{3} a_{1}-\frac{1}{3} \omega_{C}\right)^{2}-\left(\frac{1}{3} a_{1}-\frac{1}{3} \omega_{B}\right)^{2}
\end{aligned}
$$

Expression (16) indicates the incentive for firm $i$ to increase production $q_{i}^{C}$ (decreasing nominal wage accordingly) when the rival does not adjust and keeps producing $q^{B}$ with nominal wage $w^{B}$. If it is negative, the firm adjusts, otherwise it doesn't and the economy stays in point $B$. Expression (17) tells us whether for firm $i$ it is convenient to adjust production when also the rival does, and this happens only if the r.h.s. is negative. Finally, expression (18) evaluates the Pareto efficiency in the symmetric cases (when they both adjust or don't adjust). If it is positive, in Figure 1 point $C$ is Pareto-superior to point $B$.

Given equations (8) and (11) we can rewrite (18) as:

$$
\pi_{S S}\left(\omega_{C} ; \omega_{C}\right)-\pi_{M M}\left(\omega_{B}, \omega_{B}\right)=\left(q_{i}^{C}\right)^{\frac{2}{\alpha}}-\left(q_{i}^{B}\right)^{\frac{2}{\alpha}}
$$

from which - since $q_{i}^{C}>q_{i}^{B}$ by construction - we infer that: $\pi_{S S}\left(\omega_{C} ; \omega_{C}\right)-$ $\pi_{M M}\left(\omega_{B}, \omega_{B}\right)>0$ and $\omega_{C}<\omega_{B=A}$. That is, the symmetric adjustment to point $C$ is always Pareto-superior to the symmetric non-adjustment in point $B$. Also, we know that the real wage after the adjustment is lower than the real wage before and after the negative demand shock.

The characterization of the equilibrium of the first stage as well as the subgame perfect equilibrium of the two-stage game is given by the four possible combinations of the signs of expressions (16) and (17). We therefore proceed to analysing the sign of both expressions with respect to $\omega_{C} \in\left(0, \omega_{B}\right)$ in order to define the equilibrium outcome as a function of the real wage level that would occur at the end of the adjustment process. 
Looking at the payoff matrix, we know that:

if $\left\{\begin{array}{l}(16)<0 \\ (17)<0\end{array}\right\} \rightarrow$ equilibrium is in point $C$ (symmetric adjustment)

if $\left\{\begin{array}{l}(16)>0 \\ (17)>0\end{array}\right\} \rightarrow$ equilibrium is in point $B$ (no adjustment)

if $\left\{\begin{array}{l}(16)<0 \\ (17)>0\end{array}\right\} \rightarrow$ chicken game (asymmetric adjustment)

if $\left\{\begin{array}{l}(16)>0 \\ (17)<0\end{array}\right\} \rightarrow$ coordination game (two equilibria with symmetric choi(es)

\section{Equilibrium analysis}

As our aim is to analyze the determination of the four outcomes according to the equilibrium real wage after the symmetric adjustment, we study the signs of expressions (16) and (17) in a space where both curves are plotted againts the level of $\omega_{C}$. We can immediately establish by visual inspection that $\pi_{M M}\left(\omega_{B}, \omega_{B}\right)-\pi_{S M}\left(\omega_{C} ; \omega_{B}\right)$ and $\pi_{M S}\left(\omega_{B} ; \omega_{C}\right)-\pi_{S S}\left(\omega_{C} ; \omega_{C}\right)$ are parabolic and concave in $\omega_{C}$. Studying the two parabola across the admissible range $\left(0, \omega_{B}\right)$, we can relate the realization of any of the above equilibria to specific values of the post-shock real wage level $\omega_{C}$. As it will turn out, there are four possible cases according to where the two parabola (16) and (17) intercept the horizontal axis on which we measure $\omega_{C}$.

We set out formulating the following:

Lemma 1 The maxima of $\pi_{M M}\left(\omega_{B}, \omega_{B}\right)-\pi_{S M}\left(\omega_{C} ; \omega_{B}\right)$ and $\pi_{M S}\left(\omega_{B} ; \omega_{C}\right)-$ $\pi_{S S}\left(\omega_{C} ; \omega_{C}\right)$ are both positive.

Proof. In order for the horizontal intercept to exists, the maximum of the parabola (16)-(17) must be positive. Their partial derivatives with respect to $\omega_{C}$ read:

$$
\begin{aligned}
& \frac{\partial\left[\pi_{M M}\left(\omega_{B}, \omega_{B}\right)-\pi_{S M}\left(\omega_{C} ; \omega_{B}\right)\right]}{\partial \omega_{C}}=\frac{2^{\frac{-2+\alpha}{\alpha}}\left(2^{\frac{1}{\alpha}}-1\right)\left(2 a_{1}+\omega_{B}-3 \omega_{C}\right)}{3} \\
& \frac{\partial\left[\pi_{M S}\left(\omega_{B} ; \omega_{C}\right)-\pi_{S S}\left(\omega_{C} ; \omega_{C}\right)\right]}{\partial \omega_{C}}=\frac{\left(a_{1}-\omega_{B}\right)\left(3 \cdot 2^{-\frac{1}{\alpha}}+2 a_{1}-2 \omega_{C}\right)}{9}
\end{aligned}
$$


The first is nil at $\omega_{C}=\left(2 a_{1}+\omega_{B}\right) / 3$, while the second is nil at $\omega_{C}=$ $\left(3 \cdot 2^{-\frac{1}{\alpha}}+2 a_{1}\right) / 2$. Plugging these values back into (16) and (17), these simplify as follows:

$$
\frac{\frac{a_{1}-\omega_{B}}{9}>0}{\left[9 \cdot 4^{-\frac{1}{\alpha}}+\left(a_{1}-\omega_{B}\right)\left(8+2^{2-\frac{1}{\alpha}}\right)\right]\left(a_{1}-\omega_{B}\right)}>0 .
$$

The expressions in (24) confirm that the maxima are indeed positive and also imply the existence of two horizontal intercepts for each parabola. We can label them $\left(\omega_{C 1} ; \omega_{C 2}\right)$ for parabola $(16)$ and $\left(\omega_{C 3} ; \omega_{C 4}\right)$ for parabola (17). They can be identified by setting the two equations equal to zero and solving for $\omega_{C}$. At this point, we can introduce a useful definition which will facilitate the intuition later on. Since in the industrial organization literature it is common to think of the difference between the reservation price and the marginal cost as the market size, we define:

$$
a_{1}-\omega_{B}=s>0
$$

which therefore indicates the size of the market after the occurrence of the negative demand shock.

Lemma 2 Provided $s<\widehat{s}$, there exists a single value of $\omega_{C} \in\left(0, \omega_{B}\right)$ at which $\pi_{M M}\left(\omega_{B}, \omega_{B}\right)-\pi_{S M}\left(\omega_{C} ; \omega_{B}\right)=0$.

Proof. For the parabola (16) - whose sign expresses the incentive for the individual firm to unilaterally adjust to point $C$ after the demand shock the two horizontal intercepts $\omega_{C}$ are:

$$
\begin{aligned}
& \omega_{C 1}=\omega_{B}+\frac{1}{3}\left[2-\frac{4^{\frac{1}{\alpha}}}{\sqrt{4^{\frac{1}{\alpha}}\left(-1+2^{\frac{1}{\alpha}}\right)}}\right] s \\
& \omega_{C 2}=\omega_{B}+\frac{1}{3}\left[2+\frac{4^{\frac{1}{\alpha}}}{\sqrt{4^{\frac{1}{\alpha}}\left(-1+2^{\frac{1}{\alpha}}\right)}}\right] s
\end{aligned}
$$

As $s>0$ because of non-negativity of profits and $2^{\frac{1}{\alpha}}-1>0$ for any $\alpha>0$, the intercept $(27)$ is greater than $\omega_{B}$ and therefore outside the admissible 
set $\omega_{C} \in\left(0, \omega_{B}\right)$. We now need to verify that the intercept (26) lies in the admissible interval, that is $0<\omega_{C 1}<\omega_{B}$. If it does, then expression (16) changes sign within the relevant range of post-adjustment real wage levels, which means that the individual firm's decision to unilaterally proceed to adjustment after the occurrence of the shock depends on how lower its marginal cost would be. If it does not, then expression (16) is greater than zero for any $\omega_{C} \in\left(0, \omega_{B}\right)$ and therefore for the individual firm is never convenient to unilaterally adjust, no matter how low the marginal cost would become. Since the term $\frac{1}{3}\left[2-4^{\frac{1}{\alpha}} / \sqrt{4^{\frac{1}{\alpha}}\left(-1+2^{\frac{1}{\alpha}}\right)}\right]$ is negative for any $\alpha>0$, then $\omega_{C 1}<\omega_{B}$.

Furthermore, $\omega_{C 1}>0$ for all:

$$
s<\frac{3 \omega_{B} \sqrt{2^{2 / \alpha}\left(2^{1 / \alpha}-1\right)}}{2^{2 / \alpha}-2 \sqrt{2^{2 / \alpha}\left(2^{1 / \alpha}-1\right)}} \equiv \widehat{s} .
$$

Thus, if indeed condition (28) is satisfied, then $\omega_{C 1} \in\left(0, \omega_{B}\right)$, and the real wage level after the adjustment process is relevant in determining whether the firm unilaterally decides to exploit the trade-off after the occurrence of the negative demand shock: for all $\omega_{C}<\omega_{C 1}$ (i.e., if marginal cost is sufficiently low to ensure that the adjustment is profitable) the firm adjusts no matter what the rival does.

Turning now to the parabola (17), we can prove the following:

Lemma 3 Provided $s<\widetilde{s}$, there exists a single value of $\omega_{C} \in\left(0, \omega_{B}\right)$ at which $\pi_{M S}\left(\omega_{B} ; \omega_{C}\right)-\pi_{S S}\left(\omega_{C} ; \omega_{C}\right)=0$.

Proof. Solving $\pi_{M S}\left(\omega_{B} ; \omega_{C}\right)-\pi_{S S}\left(\omega_{C} ; \omega_{C}\right)=0$, one obtains the two horizontal intercepts

$$
\begin{aligned}
& \omega_{C 3}=\omega_{B}+2^{-\frac{1+\alpha}{\alpha}}\left(3+2^{\frac{\alpha+1}{\alpha}} s\right)-\sqrt{9+2^{\frac{2 \alpha+1}{\alpha}}\left(1+2^{\frac{\alpha+1}{\alpha}}\right) s} \\
& \omega_{C 4}=\omega_{B}+2^{-\frac{1+\alpha}{\alpha}}\left(3+2^{\frac{\alpha+1}{\alpha}} s\right)+\sqrt{9+2^{\frac{2 \alpha+1}{\alpha}}\left(1+2^{\frac{\alpha+1}{\alpha}}\right) s}
\end{aligned}
$$

We can note by visual inspection that $\omega_{C 4}>\omega_{B}$ and therefore outside the admissible interval $\omega_{C} \in\left(0, \omega_{B}\right)$. As for $\omega_{C 3}$, it is always positive for any $\alpha>0$. Moreover, we derive from (29) that $\omega_{C 3}<\omega_{B}$ for all

$$
s<2\left(1-2^{-\frac{1}{\alpha}}\right) \equiv \widetilde{s} .
$$


Thus, if condition (31) is satisfied, then $\omega_{C 3} \in\left(0, \omega_{B}\right)$, and expression (17) switches sign within the admissible interval of post-adjustment real wage level. That is, the real wage level after the adjustment is relevant in determining whether the individual firm has the incentive to adjust production when the rival has already done it. For all $\omega_{C}>\omega_{C 3}$ (marginal cost would anyway be too high to preserve profitability) the firm does not have such an incentive even if the rival has indeed adjusted.

Therefore, provided that $\omega_{C 1}, \omega_{C 3} \in\left(0, \omega_{B}\right)$ - which occurs for given restrictions on the post-shock market size - it is clear that the position of $\omega_{C 3}$ with respect to $\omega_{C 1}$ is crucial in determining the spectrum of equilibrium outcomes (19)-(22) which are actually achievable in the game. In fact, for any of the intervals in the range $\omega_{C 3} \in\left(0, \omega_{B}\right)$ marked by the thresholds $\omega_{C 1}$ and $\omega_{C 3}$ we have each of the situations described by (19)-(22). Graphically:

Figure 2 Profit differential against post-adjustment real wage level, $i, j=1,3$

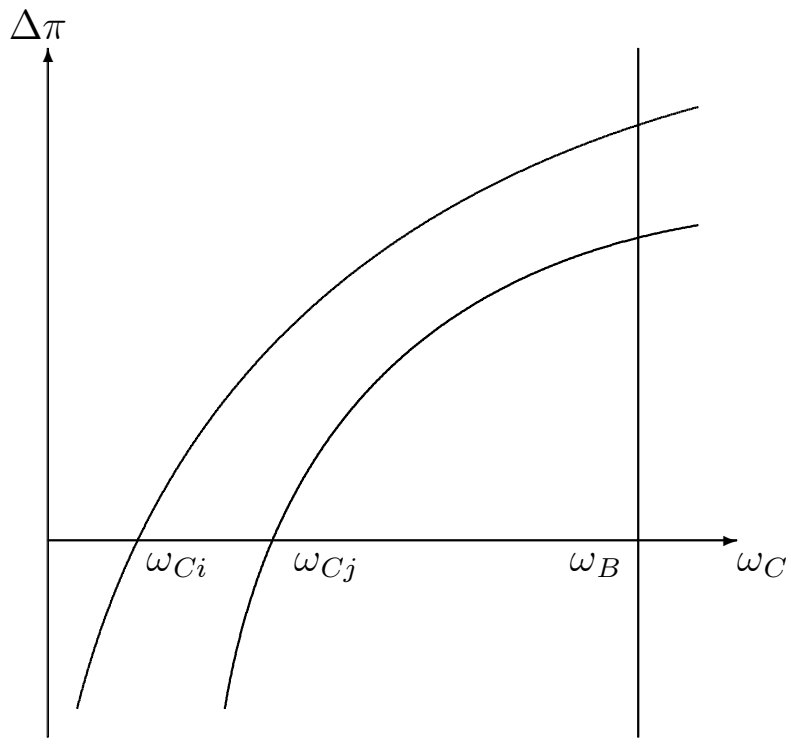


If $i=1, j=3$ we have the following order of equilibria:

$$
\begin{aligned}
\text { for any } 0 & <\omega_{C}<\omega_{\mathrm{Ci}} \text { : point } \mathrm{C} \text { (Figure 1) } \\
\text { for any } \omega_{\mathrm{Ci}} & <\omega_{C}<\omega_{C j} \text { : coordination equilibrium } \\
\text { for any } \omega_{C j} & <\omega_{C}<\omega_{B}: \text { point } \mathrm{B} \text { (Figure 1) }
\end{aligned}
$$

If instead $i=3, j=1$ then in the intermediate range of post-adjustment real wage $\left(\omega_{C 3}<\omega_{C}<\omega_{C 1}\right)$ we have a chicken game (rathen than a coordination game). The other two possible outcomes remain the same: if $\omega_{C}$ is sufficiently low we observe a symmetric adjustment, whereas if it is sufficiently high none of them does.

It is now convenient to order the two thresholds $\widetilde{s}$ and $\widehat{s}$. As next figure shows, $\widehat{s}-\widetilde{s}>0$ for very reasonable values of $\omega_{B}$.

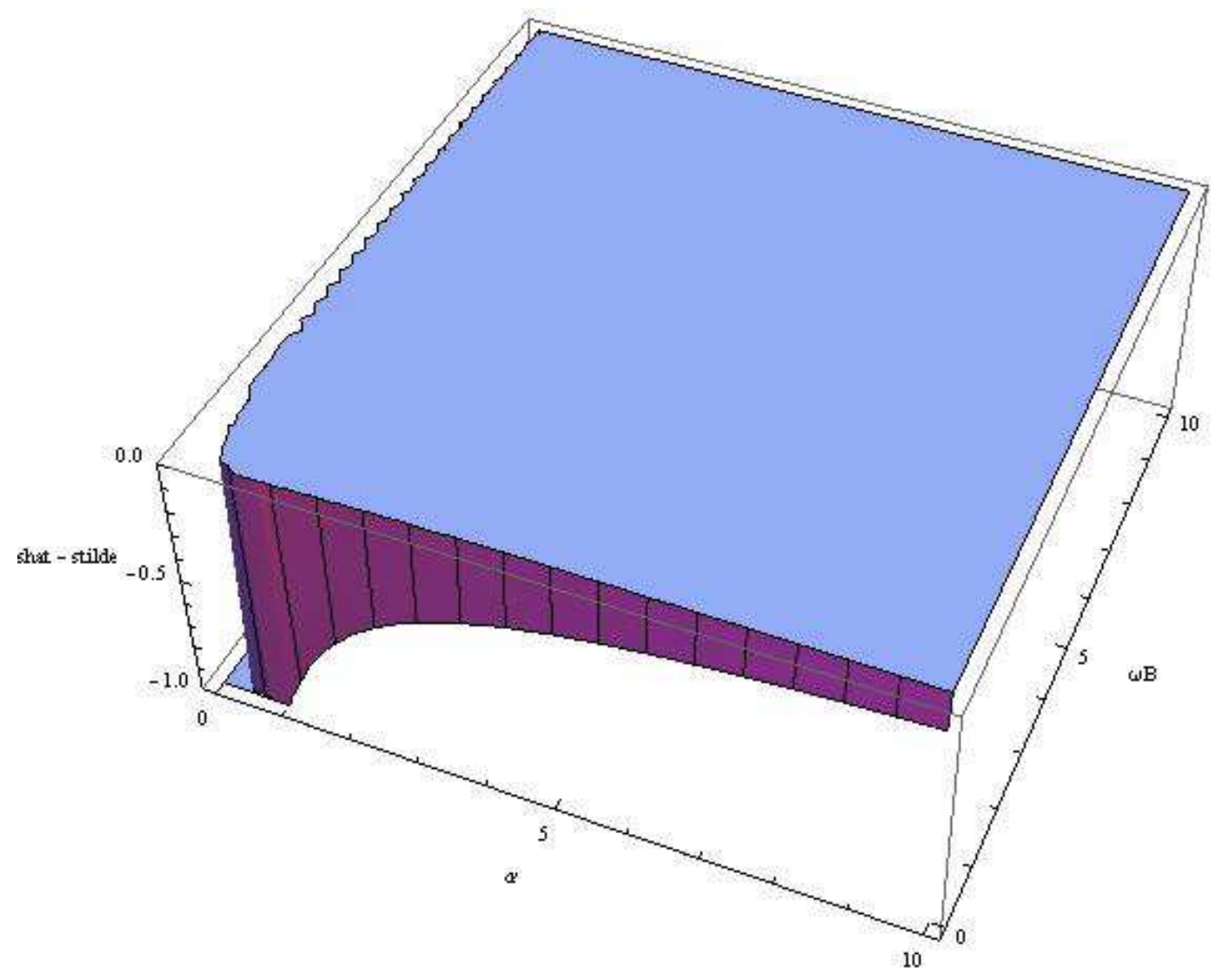

Figure $3 \widehat{s}-\widetilde{s}$ 
The following proposition states the conditions under which any of the two cases depicted in Figure 2 occurs, provided that $s<\widetilde{s}$ (so that $\omega_{C 1}, \omega_{C 3} \in$ $\left.\left(0, \omega_{B}\right)\right)$

Proposition 4 For all $s<\bar{s}<\widetilde{s}$ the thresholds on the post-adjustment real wage are ordered as follows: $0<\omega_{C 3}<\omega_{C 1}<\omega_{B}$ and we observe:

I a unique equilibrium in dominant strategies in $(S, S)$, for all $\omega_{C} \in\left[0, \omega_{C 3}\right)$. In this range, $\pi_{S S}\left(\omega_{C} ; \omega_{C}\right)>\pi_{M M}\left(\omega_{B}, \omega_{B}\right)$ and therefore $(S, S) \succ$ $(M, M)$;

II. a chicken game with two pure-strategy equilibria along the secondary diagonal, $(M, S)$ and $(S, M)$, and a mixed-strategy equilibrium, for all $\omega_{C} \in\left(\omega_{C 3}, \omega_{C 1}\right)$

III. a unique equilibrium in dominant strategies in $(M, M)$, for all $\omega_{C} \in$ $\left(\omega_{C 1}, \omega_{B}\right]$. In this range, $\pi_{M M}\left(\omega_{B}, \omega_{B}\right)>\pi_{S S}\left(\omega_{C} ; \omega_{C}\right)$ and therefore $(M, M) \succ(S, S)$.

Proof. See Appendix A.

The above proposition holds for the most realistic set of technology parameters, as it applies to the cases of decreasing, constant and (a very large range of) increasing returns to scale $(\alpha<3.106)$. The equilibrium outcome depends on the real wage level $\omega_{C}$ that would result after the completion of the adjustment process, if it actually takes place. After the demand shock, the real wage level is $\omega_{B}>\omega_{A}$. In order to facilitate the intuition, we can think of the adjustment as a trade-off taking place within the bargaining process between firms and trade-unions: as the nominal wage decrease, firms increase production (and labor) which, in turn, decreases nominal price. The combined effect is certainly a real wage decrease (as we proved earlier that $\left.\omega_{C}<\omega_{B}\right)$, but what matters for the actual realization of the adjustment is the magnitude of this decrease. Indeed, all of this boils down to assessing the final level of the real wage: if $\omega_{C}$ becomes small enough (case I), both firms find it convenient to adjust and the economy achieves point $\mathrm{C}$ in Figure 1; if $\omega_{C}$ does not decrease very much (case III), then both firms are better of without adjustment, and the economy stays in point $B$; finally, for any intermediate levels of post-adjustment real wage (case II), only one firm proceeds to adjustment. 
Proposition 5 For all $\bar{s}<s<\widetilde{s}$ the thresholds are ordered as follows: $0<\omega_{C 1}<\omega_{C 3}<\omega_{B}$, and we observe:

I. a unique equilibrium in dominant strategies in $(S, S)$, for all $\omega_{C} \in\left[0, \omega_{C 1}\right)$. In this range, $\pi_{S S}\left(\omega_{C} ; \omega_{C}\right)>\pi_{M M}\left(\omega_{B}, \omega_{B}\right)$ and therefore $(S, S) \succ$ $(M, M)$;

II. a coordination game with two pure-strategy equilibria along the main diagonal, $(M, M)$ and $(S, S)$, and a mixed-strategy equilibrium, for all $\omega_{C} \in\left(\omega_{C 1}, \omega_{C 3}\right)$. In this range, $\pi_{S S}\left(\omega_{C} ; \omega_{C}\right)>\pi_{M M}\left(\omega_{B}, \omega_{B}\right)$ and therefore $(S, S) \succ(M, M)$;

III. a unique equilibrium in dominant strategies in $(M, M)$, for all $\omega_{C} \in$ $\left(\omega_{C 3}, \omega_{B}\right]$ In this range, $\pi_{M M}\left(\omega_{B}, \omega_{B}\right)>\pi_{S S}\left(\omega_{C} ; \omega_{C}\right)$ and therefore $(M, M) \succ(S, S)$.

Proof. See Appendix B.

In this case the post-shock market size $s$ is bigger (as it is greater than the threshold $\bar{s}$ ), which is equivalent to saying that the shock has been milder. For "extreme" values of the real wage $\omega_{C}$ the equilibrium outcomes are the same as in the previous contingency: if it decreases enough, both firms proceed to adjustment, if it does not decrease enough, none of them does. For intermediate values, we have two pure-strategy equilibria along the main diagonal, corresponding to symmetric choices: either they both adjust, or they both don't. We are therefore facing a typical coordination problem. It is worth stressing that the game retains a unique mixed-strategy equilibrium for all real wage levels within the intermediate range.

Propositions 1 and 2 introduced a third threshold regarding the market size after the demand shock $(s)$. Next figure shows the size of $\bar{s}$ and $\widetilde{s}$ according to the technological parameter $\alpha$. 


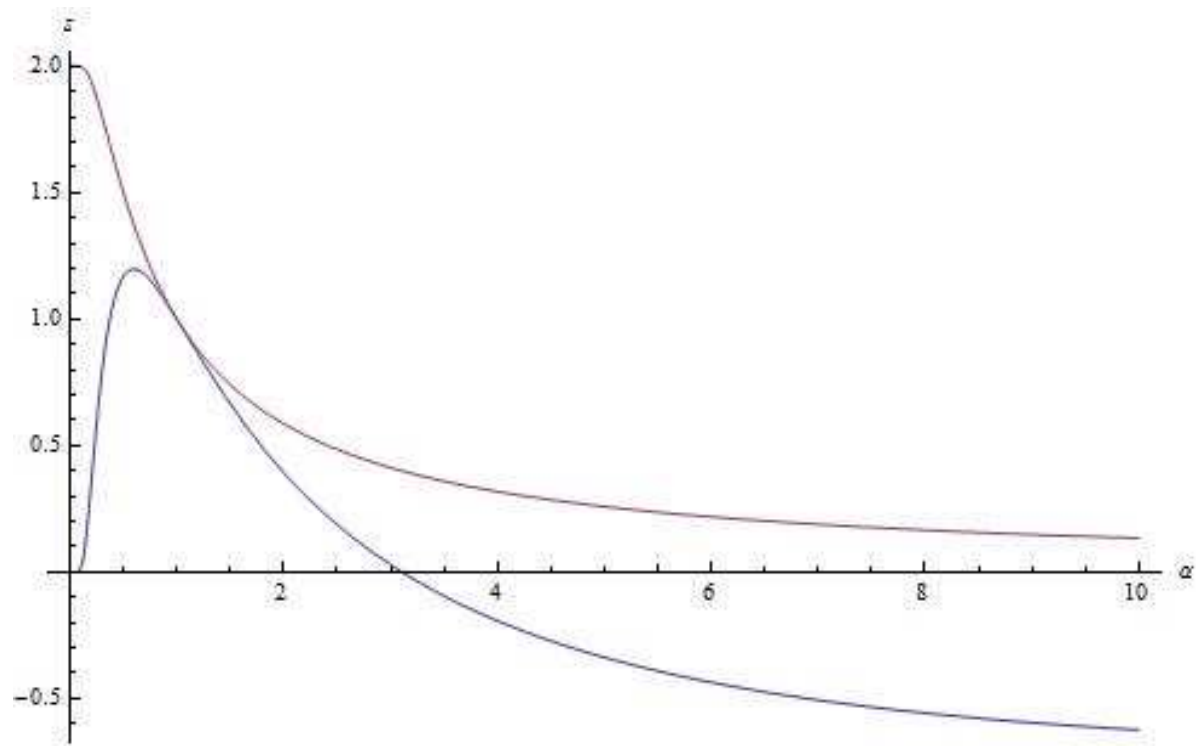

Figure 4 the shape of $\bar{s}$ and $\widetilde{s}$

Therefore $\widetilde{s}>\bar{s}$ for any $\alpha>0$. As we proved earlier than $\widehat{s}>\widetilde{s}-$ except for very low and unplausible levels of $\omega_{B}$ - then we can state that under general conditions $\widehat{s}>\widetilde{s}>\bar{s}$. Since we wanted to restrict attention to what happens when horizontal intercepts $\omega_{C 3}$ and $\omega_{C 1}$ fall within the admissible interval (and therefore the incentives for individual firms change according to the end-of-adjustment real wage level) Propositions 1 and 2 analyzed, respectively, what happens when the post-shock market size $s$ is below $s$, which is exactly the condition for $\left(\omega_{C 3}, \omega_{C 1}\right) \in\left(0, \omega_{B}\right)$. We showed that in both cases for "low" and "high" levels of $\omega_{C}$ the economy achieves, respectively, point $\mathrm{C}$ and point $\mathrm{B}$ in Figure 1 (complete adjustment or no adjustment). For intermediate values of $\omega_{C}$, depending on $s$ being below or above $s$ (that is, according to the shock size), we have either two equilibria on the secondary diagonal ("chicken game") or two equilibria on the main diagonal ("coordination game").

What remains to be analysed is what happens when the size of the shock is particularly small (i.e. when the post-shock market size remains particularly large). Given the ordering in the vector of thresholds $\{\bar{s}, \widetilde{s}, \widehat{s}\}$, this amounts to check the range of equilibria when i) $\widetilde{s}<s<\widehat{s}$ ii) $s>\widehat{s}$ :

Proposition 6 For all $\widetilde{s}<s<\widehat{s}$ the thresholds are ordered as follows: $0<\omega_{C 1}<\omega_{B}<\omega_{C 3}$, and we observe: 
I a unique equilibrium in dominant strategies in $(S, S)$, for all $\omega_{C} \in\left[0, \omega_{C 1}\right)$. In this range, $\pi_{S S}\left(\omega_{C} ; \omega_{C}\right)>\pi_{M M}\left(\omega_{B}, \omega_{B}\right)$ and therefore $(S, S) \succ$ $(M, M)$;

II a coordination game with two pure-strategy equilibria along the main diagonal, $(M, M)$ and $(S, S)$, and a mixed-strategy equilibrium, for all $\omega_{C} \in\left(\omega_{C 1}, \omega_{B}\right)$. In this range, $\pi_{S S}\left(\omega_{C} ; \omega_{C}\right)>\pi_{M M}\left(\omega_{B}, \omega_{B}\right)$ and therefore $(S, S) \succ(M, M)$;

Proof. Recalling (31), we then know that if $s>\widetilde{s}$ then $\omega_{C 3}>\omega_{B}$ and therefore (see Figure 3 ) the positive values of parabola (17) lie outside the admissible interval $\left(0, \omega_{B}\right)$; therefore, $\pi_{M S}\left(\omega_{B} ; \omega_{C}\right) ; \pi_{S M}\left(\omega_{C} ; \omega_{B}\right)-$ $\pi_{S S}\left(\omega_{C} ; \omega_{C}\right) ; \pi_{S S}\left(\omega_{C} ; \omega_{C}\right)<0$ for all $\omega_{C} \in\left(0, \omega_{B}\right)$. At the same time, as $s<\widehat{s}$ then $\omega_{C 1}>0$ because of (28), so that the parabola (16) switches sign within the range $\omega_{C} \in\left(0, \omega_{B}\right)$ and it does so at the point $\omega_{C}=\omega_{C 1}$ Therefore for any $\omega_{C}<\omega_{C 1}$ we have both (16) and (17) negative and therefore a unique equilibrium in $(S, S)$. For the remaining admissible values of $\omega_{C 1}<\omega_{C}<\omega_{B}$ we have (16) positive and (17) negative, and thefore a coordination game.

In this case, as the size of the shock becomes smaller (i.e.the post-shock market size remains bigger), for lower final values of $\omega_{C}$ - as it was the case in the last two Propositions - both firms adjust productions. For any other $\omega_{C}>\omega_{C 1}$ in the relevant range $\left(0, \omega_{B}\right)$, we observe a coordination game.

Proposition 7 For all $s>\widehat{s}$, the thresholds are ordered as follows: $\omega_{C 1}<$ $0<\omega_{B}<\omega_{C 3}$, and we observe only a a coordination game with two purestrategy equilibria along the main diagonal, $(M, M)$ and $(S, S)$, and a mixedstrategy equilibrium, for all $\omega_{C} \in\left(\omega_{C 1}, \omega_{C 3}\right)$. In this range, $\pi_{S S}\left(\omega_{C} ; \omega_{C}\right)>$ $\pi_{M M}\left(\omega_{B}, \omega_{B}\right)$ and therefore $(S, S) \succ(M, M)$;

Proof. If $s>\widehat{s}$ then by (28) $\omega_{C 1}<0$, and therefore parabola (16) is always positive over the admissible range $\omega_{C} \in\left(0, \omega_{B}\right)$. Moreover, as $\widetilde{s}<\widehat{s}$ by (Figure 4 ), then $s>\widetilde{s}$. In that case, by $(31) \omega_{B}<\omega_{C 3}$ and parabola (17) is always negative. Therefore the only situation achievable is a coordination game with two pure-strategy equilibria along the main diagonal. 


\section{$5 \quad$ Summing up results}

The central message of Propositions 1-4 is that the market size after the demand shock (denoted by $s=a_{1}-\omega_{B}$ ) determines the number of equilibria obtainable in the game; then, for a given $s$, the level of the real wage after the completion of the adjustment process if it were to occurr (denoted by $\omega_{C}$ ) determines which equilibrium is actually obtained within the feasible set. The following graphs summarise our results, taking into account each relevant range of $s$, as represented in Figure 5.

Figure 5 The size of the potential market after the shock

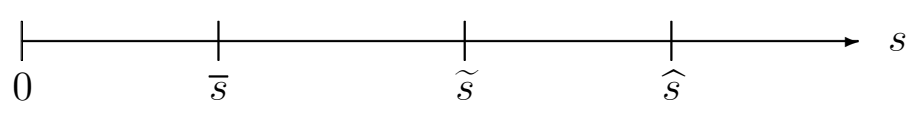

Figure 6.a portrays the situation in which the size of the potential market after the shock is very small, as a result of a particularly severe shock. Here, there surely exist a large range of $\omega_{C}$ in which at least one firm does not adjust. 
Figure 6.a $\omega_{C 1,3}$ in the interval $0<s<\bar{s}$

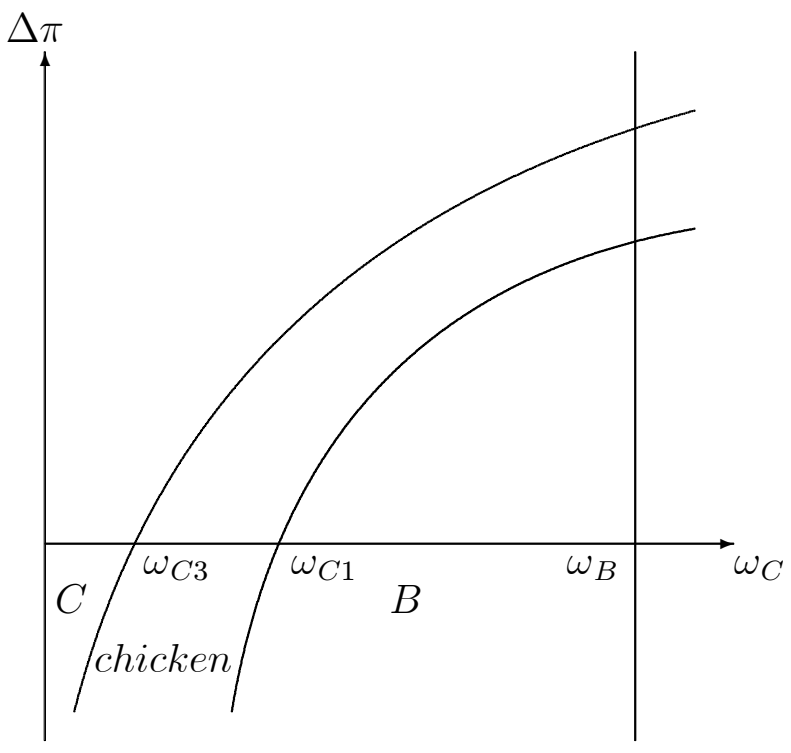

In Figures 6.b-6.d, the values of $\omega_{C}$ are such that only symmetrical equilibria may arise in pure strategies. However, since Matrix 1 can portray a coordination game with two equilibria along the main diagonal, an asymmetric equilibrium can still obtain in mixed strategies. 
Figure 6.b $\omega_{C 1,3}$ in the interval $\bar{s}<s<\widetilde{s}$

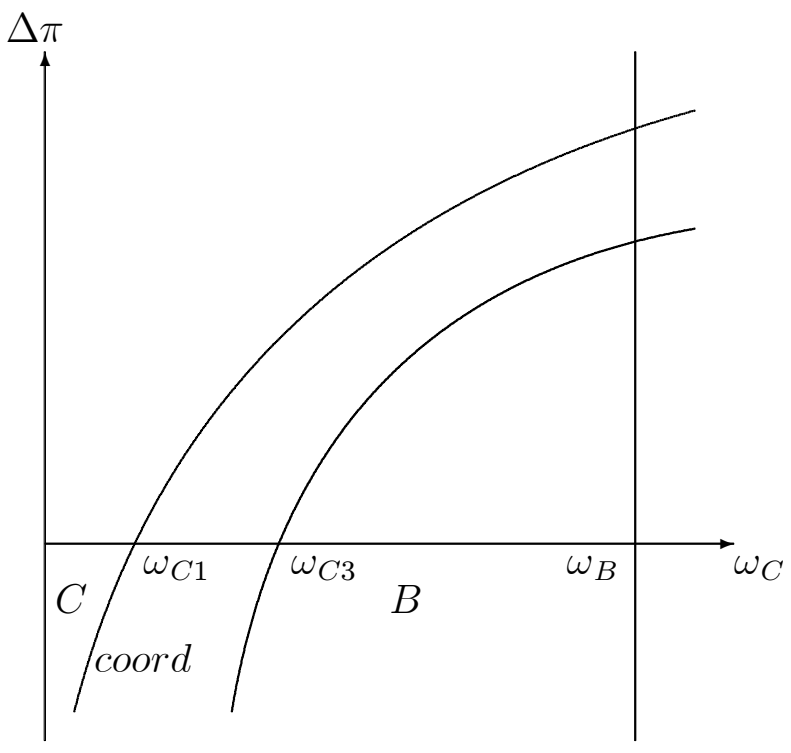


Figure 6.c $\omega_{C 1,3}$ in the interval $\widetilde{s}<s<\widehat{s}$

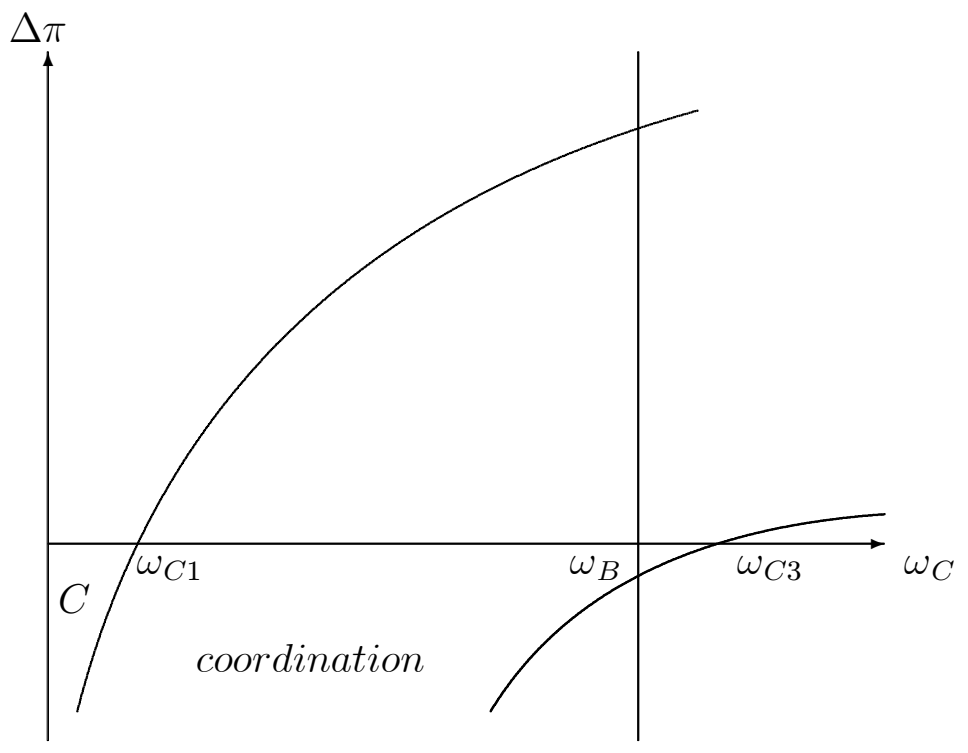


Figure 6.d $\omega_{C 1,3}$ in the interval $s>\widehat{s}$

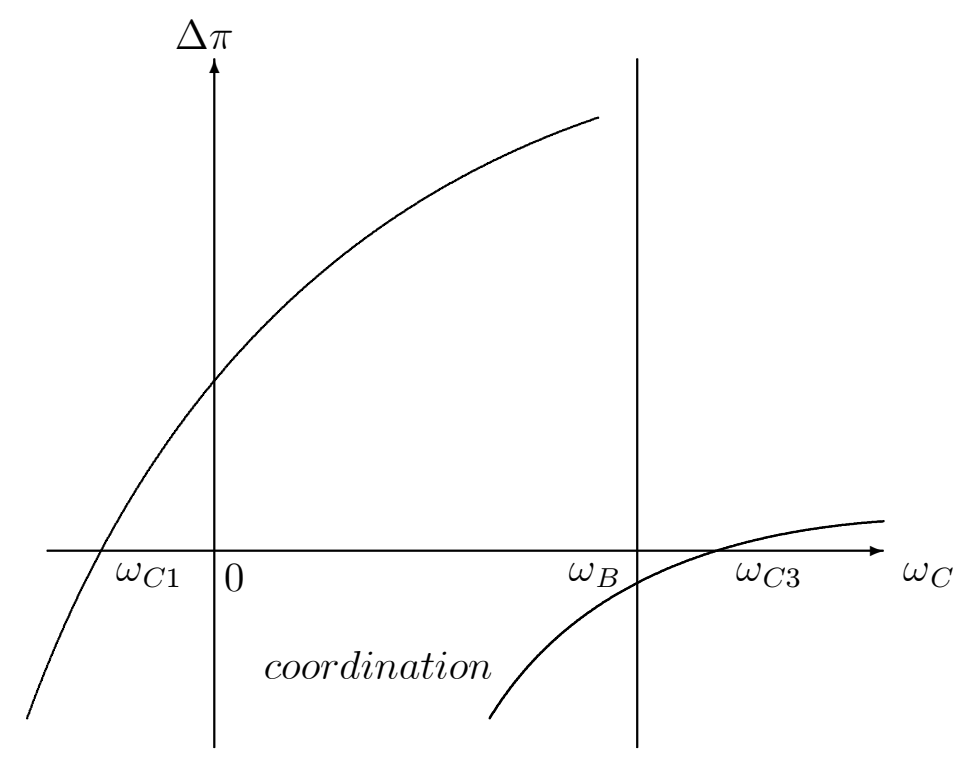

The intuition of why as $\omega_{C}$ increases the economy tends not to adjust has already been provided in the previous section: after the demand shock, firms foresee the real wage level that they would face if they decided to adjust production, and if it does not decrease enough they are better off not increasing production. What remains to be explained is the fact that - as the size of the shock decreases (i.e. $s$ increases) - for intermediate levels of $\omega_{C}$ the equilibrium outcome is the coordination game rather than the asymmetric adjustment (chicken game). Furthermore, the range of $\omega_{C}$ giving rise to the coordination game is increasing in $s$ : for all $s>\widehat{s}$ it is the only outcome attainable in the game (see Proposition 4). In other words, as the size of the shock decreases, the individual firm is increasingly less incentivized to adjust production if the rival does not do the same: either they adjust together, or none of them does. The intuition we provide is straightforward.In the asymmetric adjustment where firm 1 increases production and firm 2 does not, the price elasticity $\varepsilon_{P}$ is $\frac{a_{1}-q_{1}-q_{2}}{q_{1}+q_{2}}$. Partial derivative with respect to 
the non-adjusting firm's quantity reads $\partial \varepsilon_{P} / \partial q_{2}=-a /\left(q_{1}+q_{2}\right)^{2}<0$. So, clearly, if firm 2 does not increase $q_{2}$, the price elasticity does not decrease as firm 1 would actually want, and this effect is bigger the greater the total quantity $Q\left(=q_{1}+q_{2}\right)$. Obviously $Q$ is an increasing function of $s$, so for small demand shock (when the total quantity is still relevant), firm 1 would rather not adjust production unless firm 2 does the same.

\section{Concluding remarks}

The market-based adjustment to long-run equilibrium after a demand shock is a cornerstone of neoclassical economics, and it is often used to design policy prescriptions calling for a sufficient degree of labor market flexibility so as to speed the closing of the slack at the macroeconomic level. In this paper we have tackled the issue from a strategic interaction perspective. We have set up a non-cooperative Cournot duopoly featuring labor market rigidities where, after a negative demand shock, firms are required to choose whether to adjust production (with decreasing nominal wage) or rather to keep output and nominal wage at the pre-shock level. When faced with that strategic choice, the complete and simultaneous adjustment to long-run equilibrium is no longer guaranteed. We have shown that the size of the demand shock - as expressed by the potential market left after the shock hits the economy - determines the number and nature of equilibria generated by the game, whereas the post-adjustment real wage level (i.e. the level that it would achieve if the adjustment process were in fact to occurr) selects the equilibrium that is actually observed. Particularly, if the structural and institutional features of the economy are such that the real wage does not decrease "enough" at the end of the adjustment process, restoring the longrun equilibrium might actually be impossible. Although it lacks a formal modelling of the labor market - which we defer to future research - our model offers an alternative point of view on the mechanisms that are really at work when an economic system is hit by a negative demand shock which creates a slack. 


\section{References}

[1] Baghli, M., (2007), NAWRU and Potential Output in France, Applied Economics Letters 14, 95-98.

[2] Blanchard, O. and S. Fisher (1989), Lectures on Macroeconomics, Cambridge, MA, MIT Press.

[3] Benigno, P., (2009), New Keynesian Economics: An AS-AD View, NBER Working paper No.14824.

[4] Holden, S. and R. Nymoen (2002), Measuring Structural Unemployment: NAWRU Estimates in the Nordic Countries, Scandinavian Journal of Economics 104, 87-104.

[5] Kenen, P., (1969), The Theory of Optimum Currency Areas: An Eclectic View in R.A. Mundell and A.K. Swoboda (eds.), Monetary Problems of the International Economy, University of Chicago Press, Chicago, 41-60.

[6] McDonald, I.M., and R.M. Solow (1981), Wage Bargaining and Employment, American Economic Review 71, 896-908.

[7] McKinnon, R., (1963), Optimum Currency Areas, American Economic Review 53, 717-725.

[8] Mundell, R., (1961), A Theory of Optimum Currency Area, American Economic Review, 51, 657-665.

[9] Woodford, M., (2003), Interest and Prices. Foundations of a Theory of Monetary Policy, Princeton, NJ, Princeton University Press.

\section{APPENDIX: Proofs}

\subsection{Appendix A}

We have already established in the paper that $s<\widetilde{s}<\widehat{s}$, so that we can restrict our attention to the cases where the two horizontal intercept $\omega_{C 1}, \omega_{C 3} \in\left(0, \omega_{B}\right)$. The ordering of the two determines the equilibrium outcome which occurs for the intermediate levels of post-adjustment real wage 
$\left(\omega_{\mathrm{Ci}}<\omega_{C}<\omega_{C j}\right.$ with $\left.i, j \in(1,3)\right)$. Let's compute $\Delta \omega=\omega_{C 1}-\omega_{C 3}$ :

$$
\begin{aligned}
& \Delta \omega=2^{-\frac{1+\alpha}{\alpha}}\left(\sqrt{9+2^{2+\frac{1}{\alpha}}\left(1+2^{1+\frac{1}{\alpha}}\right) s}-3\right)-\frac{\left(2^{\frac{1}{\alpha}}+\sqrt{4^{\frac{1}{\alpha}}\left(-1+2^{\frac{1}{\alpha}}\right)}-1\right) s}{3\left(2^{\frac{1}{\alpha}}-1\right)} \\
& =\frac{1}{3\left(-1+2^{\frac{1}{\alpha}}\right)} 2^{-1-\frac{1}{\alpha}}\left[9\left(1-2^{\frac{1}{\alpha}}\right)+s\left(2^{\left(1+\frac{1}{\alpha}\right)}\left(1-\sqrt{2^{\frac{2}{\alpha}}\left(2^{\frac{1}{\alpha}}-1\right)}\right)-2^{\left(1+\frac{2}{\alpha}\right)}\right)\right. \\
& \left.-3\left(\sqrt{9+s\left(2^{\left(2+\frac{1}{\alpha}\right)}+2^{\left(3+\frac{2}{\alpha}\right)}\right)}-2^{\frac{1}{\alpha}} \sqrt{9+s\left(2^{\left(2+\frac{1}{\alpha}\right)}+2^{\left(3+\frac{2}{\alpha}\right)}\right)}\right)\right]
\end{aligned}
$$

as the term outside square brackets is positive for any $\alpha>0$, the sign of $\Delta \omega$ is the sign of the square brackets term, whose roots are:

$$
\begin{aligned}
& s=0 \\
& s=\frac{9\left[2^{1+\frac{1}{\alpha}}\left(1-3 \cdot 2^{\frac{1}{\alpha}}+4^{\frac{1}{\alpha}}+8^{\frac{1}{\alpha}}\right)-\sqrt{2^{\frac{2}{\alpha}}\left(2^{\frac{1}{\alpha}}-1\right)}\left(5 \cdot 2^{\frac{2}{\alpha}}-1-3 \cdot 2^{\frac{1}{\alpha}}\right)\right]}{2^{\frac{1}{\alpha}}\left(1-2^{\frac{1}{\alpha}}+4^{\frac{1}{\alpha}}\right)^{2}} \equiv \bar{s}
\end{aligned}
$$

Since $\bar{s}$ depends on $\alpha$, so we plot:

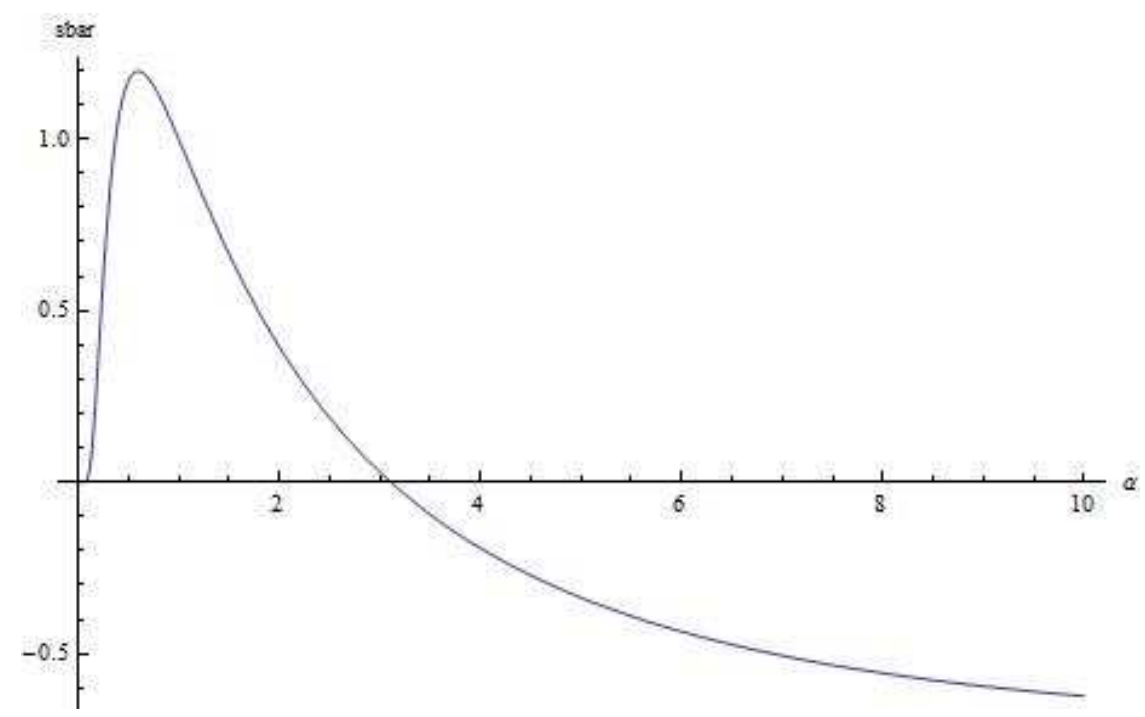

Figure A1 
which tells us that $r_{2}>0$ for any $\alpha<3.106$.

Since

$$
2^{\left(1+\frac{1}{\alpha}\right)}\left(1-\sqrt{2^{\frac{2}{\alpha}}\left(2^{\frac{1}{\alpha}}-1\right)}\right)-2^{\left(1+\frac{2}{\alpha}\right)}<0
$$

for all $\alpha>0$, we can draw the implication that $\Delta \omega$ has the following shape, for all $\alpha<3.106$ :

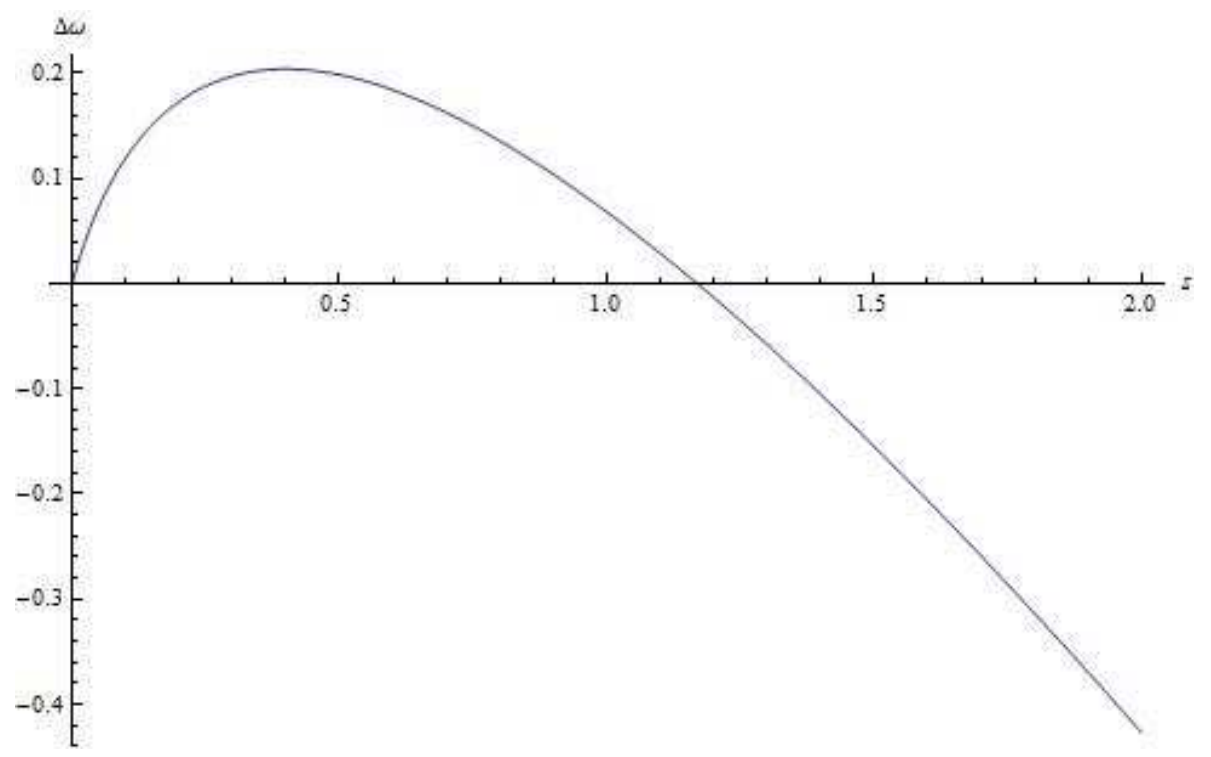

Figure A2

Consequently, we have proved that $\Delta \omega\left(=\omega_{C 1}-\omega_{C 3}\right)>0$ for any $s<\bar{s}$.

\subsection{Appendix B}

Using the proof in Appendix A, we can simply note that for any $s>\bar{s}$ the behaviour of $\Delta \omega\left(=\omega_{C 1}-\omega_{C 3}\right)$ is the following: 


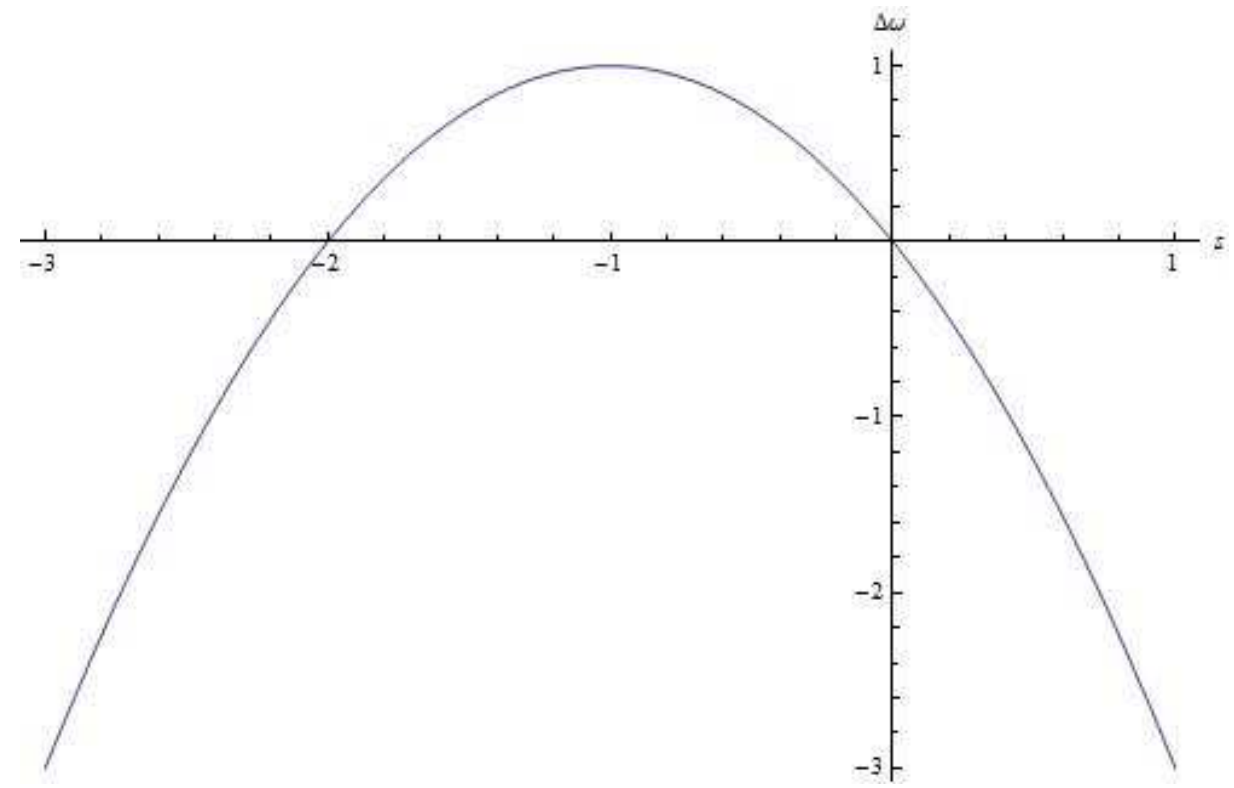

Figure A3 


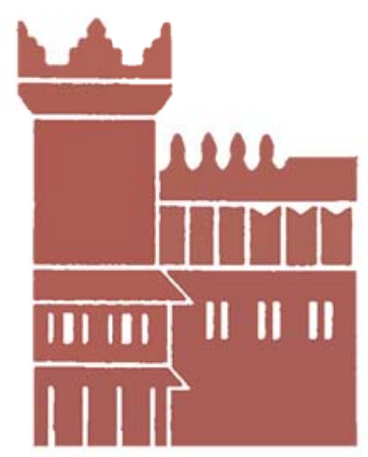

Alma Mater Studiorum - Università di Bologna DEPARTMENT OF ECONOMICS

Strada Maggiore 45

40125 Bologna - Italy

Tel. +39051 2092604

Fax +390512092664

http://www.dse.unibo.it 